\title{
O CONSUMO DIANTE DA ECONOMIA COLABORATIVA E DA UBERIZAÇÃO: RELAÇÕES DE RISCO EM UMA SOCIEDADE CONECTADA
}

\author{
Rayssa Rodrigues Lopes ${ }^{1}$ \\ Mirela Guimarães Gonçalves Couto ${ }^{2}$ \\ Márcio Eduardo Senra Nogueira Pedrosa Morais ${ }^{3}$
}

Resumo: O trabalho analisa as relações consumeristas, de modo a impulsionar o debate acerca das responsabilidades e garantias dos prestadores de serviços em relação aos consumidores diante das inovações tecnológicas baseadas na economia colaborativa e a necessidade de amparo legal nesta seara de negócios digitais. Sob a perspectiva de Bauman (2001) e Beck (2011), o artigo descreve a visão sociológica da sociedade consumerista e como é tratada no ordenamento jurídico, objetivando a garantia da segurança jurídica dos sujeitos da relação de consumo. Para tanto se utilizou o método de pesquisa dedutivohipotético, através de exposição de posicionamentos doutrinários e jurisprudenciais.

Palavras-chave: Direito do Consumidor. Uberização. Economia colaborativa. Consumo compartilhado. Risco.

\section{CONSUMPTION BEFORE COLLABORATIVE ECONOMY AND UBERIZATION: RISK RELATIONSHIPS IN A CONNECTED SOCIETY}

Abstract: The work analyzes consumer relations, in order to stimulate discussions about the responsibilities and guarantees of service providers regarding consumers in face of technological innovations based on the collaborative economy and the need for legal support in this field of digital business. From the perspective of Bauman (2001) and Beck (2011), the article describes the sociological view of consumer society and how it is treated in the Brazilian legal system, aiming at guaranteeing the legal security of the subjects of the consumption relationship. For that, the deductive-hypothetical research method was used, through the exposition of doctrinal and jurisprudential positions.

Keywords: Consumer Law. Uberization. Collaborative economy. Shared comsumption. Risk.

\section{INTRODUÇÃO}

\footnotetext{
1 Advogada. Mestranda em "Proteção dos Direitos Fundamentais" pelo Programa de Pós-graduação Stricto Sensu da Universidade de Itaúna/MG. E-mail: rayssarl@yahoo.com.br. Endereço: Avenida Antônio Olímpio de Morais, $n^{\circ}$ 234/ ap. 801, Centro - Divinópolis/MG. CEP: 35500-005. Orcid: http://orcid.org/0000-0003-05681047

2 Advogada. Mestranda em "Proteção dos Direitos Fundamentais" pelo Programa de Pós-graduação Stricto Sensu da Universidade de Itaúna/MG. E-mail: mirelacoutogg@ hotmail.com. Endereço: Rua Bahia, n. ${ }^{\circ}$ 1009, apartamento 204 - Centro - Divinópolis/MG - CEP 35500 026. Orcid: https://orcid.org/0000-0002-2940-3466

${ }^{3}$ Doutor e Mestre em Teoria do Direito (Pucminas). Especialista em Ciências Criminais (UGF) e em Direito Eleitoral (Pucminas). Coordenador e professor do PPGD Stricto Sensu da Universidade de Itaúna. Advogado. Email: marcioeduardopedrosamorais@gmail.com. Endereço: Rua Raimundo de Almeida, 394, apto 301 - Bairro Nova Vila Mozart - Itaúna-MG - Cep 35680-183. Orcid: https://orcid.org/0000-0001-7540-0138
} 
Por abordar assunto de repercussão no contexto nacional, a presente pesquisa se justifica diante do crescente número de consumidores que se utilizam dos novos métodos proporcionados pela tecnologia e pela economia colaborativa, e sendo constantemente matéria de discussão entre os estudiosos da área do Direito do Consumidor, a regulamentação das novas relações gera polêmica quanto à sua aplicação nos casos em que os consumidores necessitam de proteção.

É fundamental observar que o Direito do Consumidor possui considerável relevância dentre os ramos do Direito, haja vista conservar valores fundamentais para o ser humano, como a sua integridade física, moral, psíquica, e, por excelência, a própria vida. Nesse sentido, o Código de Defesa do Consumidor é norma de ordem pública e interesse social, ou seja, cogente, não tolerando renúncia.

Ademais, é uma lei de função social, ou seja, que não pode sofrer derrogações ou abrogações de outros diplomas legais, no que se refere à redução dos direitos dos consumidores, ainda que essas leis tenham idêntico status normativo.

Os fundamentos da defesa do consumidor estão na Constituição da República Federativa do Brasil de 1988, especificamente no artigo 5², inciso XXXII; artigo 170, inciso $\mathrm{V}$, e artigo 48 do ADCT. Acima desses, a proteção do consumidor decorre do fundamento da dignidade da pessoa humana.

É comum pensar o Direito do Consumidor apenas sob a ótica da atividade profissional, como relações entre consumidores e fornecedores, por intermédio das quais o fornecedor presta um serviço ou oferece um bem a alguém que irá consumi-lo como destinatário final.

Assim, o estudo objetiva estimular o debate acerca da autonomia, responsabilidades e garantias dos novos prestadores de serviços e verificar a eficácia dessa forma de consumo aliada aos meios possíveis de assegurar o direito do consumidor quando da existência de falha na execução de determinados serviços.

Há inicialmente uma síntese das características das relações consumeristas contemporâneas, defronte aos estudos sociológicos e do surgimento do denominado consumismo, que alterou as formas de consumo e a real necessidade de se adquirir bens e serviços. Sucede um exame dos riscos assumidos pelos sujeitos, provenientes da modernização e das relações de confiança a serem contraídas no novo modelo de negócio. 
Posteriormente, é feita uma abordagem da globalização como transformação social e a inevitável necessidade de adequação aos avanços tecnológicos provenientes da integração moderna, e então se conceitua a expressão economia colaborativa, associada às adaptações necessárias para que o modelo possa existir e progredir através das novas tecnologias e meios diversos de negociações. Aprofundando-se no novo modelo de economia, é elucidado o modelo Uber de fazer negócio, a chamada Uberização, que passa a servir de protótipo da economia colaborativa.

Por último são abordadas as formas de aplicação da norma, assim como as legislações pertinentes relacionadas ao modelo econômico e convoca-se a Constituição da República Federativa do Brasil de 1988 (CRFB/88), o Código de Defesa do Consumidor e as legislações especiais, a exemplo do Marco Civil da Internet e da Lei de Mobilidade Urbana, como sendo algumas das fontes legislativas nas quais o consumidor poderá recorrer nos casos em exame.

Por fim, a pesquisa se completa com uma ponderação para a demanda, possibilitando um consenso sobre a aplicabilidade mais razoável da norma predominante.

Para isso, é utilizado o método de pesquisa dedutivo-hipotético, através de exposição de posicionamentos doutrinários e jurisprudenciais relacionados à temática. $\mathrm{O}$ estudo se justifica diante a importância das mudanças ocorridas no cotidiano, pessoal e profissional, decorrentes das novas tecnologias.

\section{CARACTERIZAÇÃO DAS RELAÇÕES DE CONSUMO NA CONTEMPORANEIDADE}

Tal como previsto no Código de Defesa do Consumidor (BRASIL, 1990), são sujeitos das relações de consumo, o consumidor e o fornecedor de produtos e serviços. Nos termos do artigo $2^{\circ}$ do CDC, “consumidor é toda pessoa física ou jurídica que adquire ou utiliza produto ou serviço como destinatário final" (BRASIL, 1990), seja a título oneroso ou gratuito. Há ainda a figura dos consumidores equiparados, expostos nos artigos $2^{\circ}, \S$ único, art. 17 e art. 29 do CDC. Já o conceito de fornecedor encontra previsão no artigo $3^{\circ}$ do código, nos seguintes termos:

Art. $3^{\circ}$ Fornecedor é toda pessoa física ou jurídica, pública ou privada, nacional ou estrangeira, bem como os entes despersonalizados, que desenvolvem atividade de 
produção, montagem, criação, construção, transformação, importação, exportação, distribuição ou comercialização de produtos ou prestação de serviços. (BRASIL, 1990).

Segundo Sérgio Cavalieri Filho (2010), nas relações de consumo, o consumidor é o sujeito que ostenta a qualidade de vulnerável, eis que não dispõe dos mecanismos de controle do processo produtivo, participando apenas em sua última etapa, expondo-se ao risco de lesado, em sua integridade física, econômica, psicológica ou moral. De maneira semelhante, Luiz Antônio Rizzato Nunes (2018) caracteriza o consumidor como o ponto fraco mais vulnerável dos modelos de produção do livre mercado composto de consumidores e fornecedores.

As ideias de Zygmunt Bauman (2008) estão associadas às relações de consumo, de forma que se a vida social flui em um contexto de rigidez e competitividade egocêntrica, passa a haver uma ditadura do consumo, ou seja, pouco importam as pessoas como seres humanos, pois elas são tão somente clientes em potencial para movimentação da máquina capitalista para geração e acumulação de riquezas.

Os shopping centers são monumentos do consumo, onde seres humanos buscam, com alguma frequência, sustentar seus status e amparar suas angústias por intermédio da aquisição de produtos que, muitas vezes, não possuem nenhuma necessidade para aquele consumidor.

Desse modo, o consumo transforma o consumidor em mercadoria, ou seja, para participar do mercado, as pessoas são estimuladas a entrar em uma competição e as mercadorias pessoas são expostas à venda como em uma vitrine, a exemplo das redes sociais, onde pessoas querem ser consumidas por outras. Pode se considerar que atualmente as redes sociais são uma espécie de marketing pessoal. (BAUMAN, 2008).

Frente aos novos padrões de consumo, o direito do consumidor, que constitui o instrumento de equilíbrio das relações consumeristas, tende a ser adaptado à realidade com novos enfoques para articular as diversificadas negociações da sociedade moderna.

Assim, o consumidor foi alçado a alguém que possui a necessidade de consumir.

\subsection{O advento do consumismo e a necessidade de consumir}


Bauman (2001) narra a história do consumismo como a história da quebra e descarte de sucessivos obstáculos sólidos que limitam o vôo livre da fantasia e reduzem o princípio do prazer ao tamanho ditado pelo princípio da realidade.

O consumismo é definido como um tipo de arranjo social, que transforma as vontades, desejos e anseios das pessoas na principal força propulsora e operativa da sociedade, e diferentemente do consumo, definido como uma característica e ocupação dos cidadãos, o consumismo é considerado um "atributo da sociedade, segundo Bauman (2008). Ele afirma que o advento do consumismo altera a ideia de liberdade.

A vida do consumidor, a vida de consumo, não se refere à aquisição e posse. Tampouco tem a ver com se livrar do que foi adquirido anteontem e exibido com orgulho no dia seguinte. Refere-se, em vez disso, principalmente e acima de tudo, a estar em movimento. (BAUMAN, 2008, p.126).

De acordo com Zygmunt Bauman duas únicas coisas são realmente irreversíveis: "Estamos em uma posição em que todos nós dependemos uns dos outros, ou seja, o que corre na Malásia, por exemplo, tem uma tremenda importância na perspectiva de vida dos jovens e São Paulo e vice-versa". (BAUMAN, 2011, 5min12s).

Desse modo, define o mundo como sendo um único território compartilhado pelos indivíduos. A segunda é que, com aproximadamente 300 anos de história moderna, com todo desenvolvimento da tecnologia moderna, a eficiência ou a capacidade humana de produzir cada vez mais e alcançar praticamente todos os recursos do planeta, o ser humano está muito perto dos limites da suportabilidade do planeta.

Bauman, em observação sobejamente repetida, relembra ter conhecido um viciado no Facebook que o contou ter feito 500 amigos em um único dia, e assim Bauman contestou que durante 86 anos de vida não fez 500 amigos: "não havia o conceito de redes, mas sim de laços humanos, que se diferem, pois a rede, ou networking conecta e desconecta de forma extremamente fácil”. (BAUMAN, 2011, 17min39s).

Ao narrar o fato, Bauman clarifica a instabilidade dos desejos e a insaciabilidade das necessidades, as quais se harmonizam com sua teoria da modernidade líquida, em que modelo de tempo é pontilhista, ou seja, inconstante, fragmentado em uma multiplicidade de instantes eternos, marcado pela falta de coesão e pelos intervalos e rupturas que separam pontos sucessivos e a consequente necessidade de modificação e adaptações. 
De acordo com Annie Leonard, "consumo significa adquirir e utilizar bens e serviços para atender necessidades", já o “consumismo refere-se à atitude de tentar satisfazer carências emocionais e sociais através de compras e demonstrar o valor pessoal por meio do que se possui". (LEONARD, 2011, p. 158-159).

À frente serão abordados os riscos provenientes da modernização social.

\subsection{Os riscos provenientes da modernização social}

De acordo com Ulrich Beck (2010), o momento vivido é de transformação contínua da sociedade industrial clássica, sociedade caracterizada pela produção e a distribuição de riquezas para uma chamada sociedade de risco, na qual a produção dos riscos domina a lógica da produção de bens.

Dentro dessa nova concepção produtiva, os riscos são mais democráticos e globalizados, tornando, deste modo, a repartição mais equilibrada. Sendo assim, ninguém, independentemente de classe social, estaria imune às ameaças produzidas e agravadas pelo progresso.

O que se espera nos diversos tipos de relacionamento na vida social é civilidade, o mínimo de confiança e reciprocidade, as quais devem aplicáveis, em tese, nas relações de consumo. Assim, Bauman faz uma comparação metafórica no seguinte sentido:

Como a aranha cujo mundo inteiro está enfeixado na teia que ela tece a partir de seu próprio abdome, o único apoio com que estranhos se encontram podem contar deverá ser tecido do fio fino e solto de sua aparência, palavras e gestos. No momento do encontro não há espaço para tentativa e erro, nem aprendizado a partir dos erros ou expectativa de outra oportunidade. (BAUMAN, 2001, p.111).

Michael Sandel (2014) trata da questão do livre mercado, fundamentada nas afirmações da liberdade e do bem-estar social, essa como argumento utilitarista para os mercados, ou seja, quando o acordo é feito livremente, sem prejudicar ninguém, se promove o bem-estar geral, de forma que "ao permitir que as pessoas realizem trocas voluntárias, estamos respeitando sua liberdade; as leis que interferem no livre mercado violam a liberdade individual”. (SANDEL, 2014, p.99).

O caput do artigo 170 da CRFB/88 dispõe que "a ordem econômica, fundada na valorização do trabalho humano e na livre iniciativa, tem por fim assegurar a todos existência 
digna, conforme os ditames da justiça social" (BRASIL, 1988), e remete aos princípios gerais da atividade econômica.

Desses princípios, interessam diretamente às questões das relações de consumo: propriedade privada; função social da propriedade; livre concorrência e defesa do consumidor, e ainda a possibilidade de exploração da atividade econômica prevista no parágrafo único. No caput do referido dispositivo legal foram citados: a garantia absoluta da "dignidade da pessoa humana e os "valores sociais do trabalho e da livre iniciativa, conforme os ditames da justiça social", ou seja, os princípios e normas constitucionais devem sempre ser interpretados de forma harmônica.

Para Nunes (2018), a livre concorrência é essencialmente uma garantia do consumidor e do mercado. Significa que para movimentar o mercado, deve haver uma busca constante para oferecer ao consumidor produtos e serviços melhores do que os de seu concorrente, tanto na qualidade quanto no preço. Além disso, outro tópico fundamental tratado também por Nunes, é o risco da atividade do empreendedor, característica fundamental da produção na sociedade capitalista contemporânea.

\begin{abstract}
Os negócios implicam risco. Na livre iniciativa, a ação do empreendedor está aberta simultaneamente ao sucesso e ao fracasso. [...] Um risco mal calculado pode levar o negócio à bancarrota. Mas o risco é dele. É claro que são muitas as variáveis em jogo, que terão de ser avaliadas, tanto mais se existir uma autêntica competitividade no setor escolhido. (NUNES, 2018, p.146).
\end{abstract}

Evidentemente, tanto quem oferece um serviço quanto quem contrata, assume os riscos. Os riscos na contemporaneidade representam oportunidades de mercado, uma vez que se baseiam no conhecimento, tendo a ciência um papel central no avanço da sociedade. Neste sentido, é relevante a afirmação de Beck:

[...] aumenta a importância social e política do conhecimento, e consequentemente do acesso aos meios de forjar o conhecimento (ciência e pesquisa) e disseminá-lo (meios de comunicação de massa). A sociedade de risco é, nesse sentido, também a sociedade da ciência, da mídia e da informação. Nela, escancaram-se assim novas oposições entre aqueles que produzem definições de risco e aqueles que as consomem. (BECK, 2010, p. 56).

Embora reconheça o risco como elemento capaz de ser mensurável e calculável segundo leis de probabilidade, Ulrich Beck entende a sociedade de risco como sendo um mundo de incertezas fabricadas, através de inovações tecnológicas e respostas sociais 
aceleradas, produzindo um novo cenário de incertezas e de risco global, o que abre espaço para futuros alternativos. Segundo ele, os riscos tendem a gerar uma cultura civil de responsabilidade que ultrapasse os conflitos internos.

\section{GLOBALIZAÇÃO E IMPRESCINDIBILIDADE DE ADEQUAÇÃO}

Bauman traz a idéia de globalização como "o que está acontecendo a todos nós". (BAUMAN, 1999, p.57). Não é mais preciso sair para viajar: pode-se conectar a internet do computador ou do celular, receber e enviar mensagens para qualquer lugar do planeta. Como já se tornou hábito, a maioria das pessoas se encontra em movimento mesmo quando estão fisicamente paradas sentadas no sofá de suas casas, trocando os canais de TV, ao visitar espaços estrangeiros de forma extremamente rápida e até mesmo em tempo real. A informação passa a fluir independentemente dos seus portadores.

O significado mais profundo transmitido pela ideia da globalização, de acordo com Bauman (1999), é o do caráter indeterminado, indisciplinado e de autopropulsão dos assuntos mundiais; a ausência de um centro de gerenciamento. O vocábulo globalização se refere, portanto, aos efeitos globais, notoriamente não pretendidos e imprevistos.

O Papa Franscisco, na Carta Encíclica Laudato Si (2015) trata da globalização da tecnologia como um "superdesenvolvimento dissipador e consumista que contrasta com situações de miséria desumanizadoras", (IGREJA CATÓLICA, 2015) ele afirma que "a vida passa a ser uma rendição às circunstâncias condicionadas pela técnica, entendida como o recurso principal para interpretar a existência”. (IGREJA CATÓLICA, 2015). Ele estabelece que, na origem das dificuldades do mundo atual, está uma tendência de estruturar "a tecnociência segundo um paradigma de compreensão que condiciona a vida das pessoas e o funcionamento da sociedade", (IGREJA CATÓLICA, 2015) o que influência os estilos de vida e conduz as possibilidades sociais na linha dos interesses de determinados grupos de poder.

A partir da demanda descontrolada pela produção e a luta pela permanência dos bens e serviços no mercado de consumo, houve muitas alterações no universo jurídico, o mundo passara a caminhar no tempo das máquinas, "pois, com a necessidade de se produzir em larga escala, em tempo cada vez mais reduzido; a negociação entre fornecedor e consumidor teve que se adequar a esse novo ritmo”. (PASQUALOTTO; BUBLITZ, 2017). 
Segundo Paula Santos de Abreu (2005), os países em desenvolvimento, como o Brasil, que lutam para atingir maior equilíbrio de suas balanças comerciais, tendem a sofrer maior impacto com as exigências exigidas em relação a demandas de proteção ao consumidor de países mais desenvolvidos. Em contrapartida, as medidas forçam o país a se modernizar para competir no mundo globalizado e oferecer à sua sociedade produtos de alta qualidade e preços mais baixos.

\subsection{Economia Colaborativa aliada às adaptações tecnológicas}

A economia colaborativa é basicamente uma forma de utilizar a tecnologia para incentivar as pessoas a fazerem negócios entre elas. Com o enraizamento da tecnologia e a constante inovação, surgem novos modelos de negócios, que se integram à indústria por diferentes formatos, baseada principalmente nos recursos digitais e suas competências.

O novo meio de relação permite uma lógica colaborativa e participativa, onde é possível consumir sem necessariamente ter a posse dos bens, compartilhar serviços e dar mais utilidades a produtos já usados por meio das redes sociais, que conectam pessoas de todo o mundo a partir de plataformas digitais, o que potencializa a capacidade de transformação do mercado.

São plataformas online criadas para a divulgação do aluguel de bens e prestação de serviços para diversos consumidores. Além do incentivo ao compartilhamento, as redes permitem ampliar a visibilidade de produtos e serviços. Caronas, aluguel de imóveis, venda, troca e compartilhamento dos mais variados bens e serviços são alguns dos exemplos no modelo econômico colaborativo, o qual ocorre quando as pessoas participam na partilha organizada, troca, escambo, aluguel e permuta, com o objetivo de obter os mesmos prazeres da propriedade com custos e encargos reduzidos, bem como menor impacto ambiental (BOTSMAN; ROGERS, 2010).

Os consumidores têm a oportunidade de poupar por meio das plataformas, enquanto os trabalhadores, no caso dos motoristas por exemplo, podem ganhar um dinheiro extra, oferecendo serviços. De acordo com ANDRADE e DANTAS, o modelo pressupõe mudanças no perfil dos consumidores, dos trabalhadores e do contrato social: 
No que se refere aos consumidores, cabe destacar que o novo paradigma não faz questão de ter a propriedade do bem, se satisfazendo com o acesso a ele. Neste novo modelo, o acesso é mais importante que a posse. Por esta razão, esta é urna economia de acesso, onde é possível que se encontrem aplicativos oferecendo serviços de cozinheiro, manicure, cabeleireiro, médicos, hospedagem, motorista e até pessoas dispostas a passear com os cachorros de outras pessoas. (2019, p.81).

Nos moldes de algumas das empresas mais conhecidas (Uber, Airbnb e Ebay), os consumidores deixam de ter acesso a bens e serviços somente a partir das empresas e dos profissionais especializados e passam a também a serem produtores, usuários ou participantes ativos. Os serviços oferecidos são gerenciados por softwares e plataformas de propriedade das empresas, que se firmam no mercado como mediadoras entre trabalhadores e consumidores.

De acordo com Ana Cirne Paes de Barros, na essência das práticas de consumo colaborativo estão quatro princípios:

1) Massa crítica: a existência de mercadorias suficientes para darem a sensação de escolha para o consumidor; 2) Capacidade ociosa: o aproveitamento de algo que não está sendo utilizado ou aproveitado e pode ser redistribuído; 3) Crença no bem comum: a crença no equilíbrio entre o interesse dos indivíduos com o interesse dos grupos e 4) Confiança entre estranhos: os intermediários devem criar ferramentas e ambientes para que as pessoas confiem umas nas outras. (BARROS, 2015, p. 6).

O consumo colaborativo decorre de uma sucessão de fatores históricos, culturais, econômicos, sociais e tecnológicos, a sociedade em rede, a interação e conexão entre pessoas que faz crer que a colaboração está em evolução continuamente, principalmente no âmbito das mídias digitais. Muito além do fato de implicarem na atuação dos indivíduos, estas práticas relevam uma reconfiguração no modelo de negócios, na forma como empresas e cidadãos se relacionam, na conscientização a respeito do consumo e das relações sociais e políticas.

Originalmente, o modelo da economia compartilhada era progressista, com fulcro ambiental sustentável. Porém, tal modelo passou a ser parte de um ecossistema socioeconômico dominado pelo uso de computação e tecnologia para coordenar forças de trabalho e criar cadeias de fornecimento globais a partir do uso das posses pessoais, permitindo trocas e formação de comunidades, sendo uma alternativa às grandes corporações. 
Não obstante, o cenário também revela pontos desfavoráveis, como exemplo a quebra da relação de emprego, o que acaba privando os trabalhadores das garantias trabalhistas, além de algumas barreiras como as analisadas em uma pesquisa realizada pela CNDL e SPC Brasil no período de 24 de maio a 06 de junho de 2019 com 837 internautas, a qual constatou:

\begin{abstract}
$\mathrm{Na}$ economia compartilhada os limites éticos e a construção das relações de confiança estão constantemente em pauta, uma vez que são a base para que as transações ocorram de maneira favorável e sem prejuízo para nenhuma das partes. Neste sentido, $61,1 \%$ acreditam que o consumo colaborativo pode ter problemas, porque as pessoas não são confiáveis no Brasil. Dentre as principais barreiras encontradas estão a falta de confiança nas pessoas, o medo de ser passado para trás $(44,9 \%)$, a falta de informação $(42,7 \%)$, o perigo de lidar diretamente com pessoas estranhas $(37,9 \%)$ e a falta de garantias em caso de não cumprimento do acordo $(33,3 \%)$. (SPC BRASIL, 2019).
\end{abstract}

Estudada a economia colaborativa aliada às adaptações tecnológicas, passa-se, na próxima subseção, ao estudo do fenômeno da uberização.

\title{
3.2 Fenômeno da Uberização como protótipo do modelo
}

Ainda que o aspecto inicial não deixe claro, segundo David Silva Franco e Deise Luiza da Silva Ferraz (2019), a uberização consiste basicamente na venda da força de trabalho. Embora a uberização não se restrinja à atividade da Uber, mas também aos diferentes modelos de empresas-aplicativo que estabelecem este mesmo padrão de relações de trabalho sem uma regularização, o estudo aprofundado se vale pela abrangência global do modelo de negócio da empresa que dá o nome ao fenômeno. De acordo com Dara Khosrowshahi:

\footnotetext{
A ascensão dos smartphones, o advento das lojas de aplicativos e o desejo de trabalhar sob demanda sobrecarregaram o crescimento da Uber e criaram um padrão totalmente novo de conveniência para o consumidor. O que começou como "Toque em um botão, pegue uma carona" se tornou algo muito mais profundo: compartilhamento de carona e carona; entrega de refeições e frete; bicicletas e scooters elétricas; carros autônomos e aviação urbana. (KHOSROWSHAHI, 2020).
}

Diante do contexto da popularização do acesso aos aplicativos de smartphones, a empresa Uber surgiu, em 2008, nos Estados Unidos da América com uma primeira ideia bem simples: existem muitas pessoas com tempo disponível para trabalhar como motoristas e há 
demanda de passageiros. Pelo aplicativo Uber, com poucos toques no smartphone o motorista vem e conduz o usuário ao destino solicitado, com o pagamento realizado de forma segura por cartão de crédito cadastrado pelo cliente, em que o motorista recebe o valor já com os descontos. A menos que diversamente acordado pela Uber, os serviços são disponibilizados para o uso pessoal e não comercial.

Mesmo permitindo autonomia do trabalhador que executa o serviço, ao ter acesso à gestão do trabalho pelo aplicativo, a empresa detém grande poder de controle. O motorista arca com os custos e riscos de sua profissão, mantendo-se subordinado. Na compra da força de trabalho, a Uber não paga os custos de produção necessários para desenvolver a atividade, os quais são dos próprios motoristas, além de haver remuneração apenas quando há a afetiva prestação do serviço. A atividade dos motoristas é um tipo de cooperação gerida pela empresa. É exigido que os motoristas sigam uma série de padrões estabelecidos, onde o supervisor do trabalho é o próprio cliente, já que o serviço é uma mercadoria consumida simultaneamente à sua produção. Por meio das interações e avaliações no aplicativo, a empresa consegue controlar os registros dos clientes, e conforme avaliado, ou se rejeitar corridas, por exemplo, o motorista pode ser suspenso ou desligado como forma de punição. Assim, a uberização garante facilidades e promove relações mais próximas entre oferta e demanda.

Segundo expõe Ana Carolina Reis Paes Leme (2019, p.2019), o sistema Uber seduz ao vender um sonho de trabalho autônomo, "com liberdade, sem burocracias no pagamento, já que o condutor recebe na semana seguinte ou até pode receber na semana corrente à prestação de serviço". Porém é necessário que o motorista se mantenha no padrão exigido pela Uber, inclusive conseguir sustentar uma alta pontuação no aplicativo.

Diferente do que ocorre na economia colaborativa em geral, no modelo Uber, "o usuário do aplicativo não tem a opção de escolha quanto ao motorista que lhe conduzirá ao destino desejado, ou seja, os clientes não podem ser fidelizados pelos motoristas, mas somente ligados, aleatoriamente, por meio do aplicativo". (P.105, ALVES).

Não há como questionar os benefícios trazidos pelas inovações tecnológicas, a "universalização" do acesso à telefonia, por exemplo, permitiu um aumento da qualidade na oferta, além da maior facilidade de aquisição de bens e serviços.

A ideia original de consumo colaborativo foi preliminarmente aclamada como uma saída sustentável, o que leva a questionar se a proposta da Uber como sendo um exemplo de 
consumo colaborativo depois do crescimento desta empresa no mercado, ainda pode ser considerada como um componente da economia compartilhada.

\section{REGULAMENTAÇÃO E APLICAÇÃO DO CÓDIGO DE DEFESA DO CONSUMIDOR}

Assim como demonstrado por Bauman nas relações entre indivíduos e sociedade, é possível correlacionar o elo entre motoristas de aplicativo e suas respectivas empresas. "O desinteresse pelo vínculo trabalhista demonstra uma grande decadência" (FRAGOSO; BONATO; SOARES, 2020), vez que do mesmo modo que a tecnologia aproxima relações e conectam os indivíduos, tudo é naturalmente desconectado. Ou seja, "tudo é líquido, e marcado pela efemeridade e a insegurança". (FRAGOSO; BONATO; SOARES, 2020).

Sobre a constitucionalidade e legalidade dos serviços de transporte privado, tal como os prestados pela Uber, há fundamentação nos artigos 5, XIII da CRFB/1988, o qual estabelece que "é livre o exercício de qualquer trabalho, ofício ou profissão, atendidas as qualificações profissionais que a lei estabelecer" (BRASIL, 1988) e artigo 170 que dispõe sobre os princípios da livre iniciativa e livre concorrência fundamentados, entre outros, na dignidade e na defesa do consumidor.

O Recurso Especial 1054110 relatado pelo Ministro Roberto Barroso em maio de 2019, fixou duas teses no sentido de não proibir ou restringir as atividades de aplicativos como Uber, Cabify e 99 (como exemplos), nos seguintes termos:

1. A proibição ou restrição da atividade de transporte privado individual por motorista cadastrado em aplicativo é inconstitucional, por violação aos princípios da livre iniciativa e da livre concorrência; e 2. No exercício de sua competência para regulamentação e fiscalização do transporte privado individual de passageiros, os Municípios e o Distrito Federal não podem contrariar os parâmetros fixados pelo legislador federal (CF/1988, art. 22, XI).

Diante dos casos em análise, uma questão relevante é se há a possibilidade aplicar a Lei 8.078/90, vez que algumas das plataformas compartilhadas como exemplo do iFood, apenas aproximam os sujeitos da relação, sem ter interferência direta na oferta e no negócio realizado, e assim dificilmente a empresa que desenvolve a plataforma ou aplicativo poderia ser responsabilizada com base no Código de Defesa do Consumidor, por figurar apenas como 
provedor de acesso e não fornecedor, excluindo assim a responsabilidade da empresa pelos vícios dos serviços ou produtos.

Por outro lado, se o caso concreto for por exemplo, a falha na realização do negócio por culpa do aplicativo, pode e deve sim ser gerada uma responsabilidade para a empresa provedora na realização do negócio executado entre as partes.

O CDC prevê nos termos do seu artigo $4^{\circ}$, inciso III:

\begin{abstract}
A harmonização dos interesses dos participantes das relações de consumo e compatibilização da proteção do consumidor com a necessidade de desenvolvimento econômico e tecnológico, de modo a viabilizar os princípios nos quais se funda a ordem econômica (art. 170, da Constituição Federal), sempre com base na boa-fé e equilíbrio nas relações entre consumidores e fornecedores. (BRASIL, 1990).
\end{abstract}

O direito deve acompanhar a evolução da sociedade, contudo, o Brasil ainda não possui uma lei específica que verse sobre a economia compartilhada.

Com o surgimento da Lei 12.965/14, conhecida como Marco Civil da Internet, ficaram determinados como fundamento da internet brasileira: a livre iniciativa e a livre concorrência, assim como consta expressamente como princípio, a natureza participativa da rede, e a liberdade dos modelos de negócios promovidos na Internet, desde que não conflitem com os demais princípios estabelecidos na lei. O artigo $7^{\circ}$, inciso XIII assegura a aplicação do Código de Defesa do Consumidor nas relações de consumo realizadas na internet.

O Código de Defesa do Consumidor deve incidir, então, em diálogo com a Lei 12.965 de 2014 e outras fontes, como forma de garantia da segurança jurídica e da ordem social, visando ainda assegurar a adequada proteção da confiança despertada pelas novas tecnologias, como é o caso das situações de consumo colaborativo desenvolvidas por intermédio da internet.

Até a promulgação da Lei $\mathrm{n}^{\circ}$ 13.640, de 26 de março de 2018, que alterou a Lei da Mobilidade Urbana, de 2012, existia um vácuo legislativo diante das inovações tecnológicas e da dificuldade de adaptação do Direito. Foi acrescentada à lei de 2012 o inciso X do art. $4^{\circ}$ que passou a vigorar com a seguinte redação:

Transporte remunerado privado individual de passageiros: serviço remunerado de transporte de passageiros, não aberto ao público, para a realização de viagens individualizadas ou compartilhadas solicitadas exclusivamente por usuários 
previamente cadastrados em aplicativos ou outras plataformas de comunicação em rede.

De acordo com Luiz Nayjhon de Souza Oliveira e Antônio Raniel Silva Lima (2018), ao analisar os estudos nacionais mais recentes sobre o tema, o principal embate é exatamente o quesito regulamentação, onde é constatada a falta coerência entre a legislação e a situação concreta. Por outro lado, diante da tendência de crescimento do modelo colaborativo inovador, como sendo fonte econômica e beneficiária ao consumidor final, vários autores defende a necessidade de um modelo normativo específico.

\section{CONCLUSÃO}

O estudo, partindo da perspectiva de uma modernidade líquida, mostrou as diversas transformações que foram ocorrendo na sociedade, principalmente em relação ao modo de consumir, que tende a ser adaptável à modernidade no cenário em que se vive. As necessidades não são estáticas, assim como as pessoas se tornam cada vez mais exigentes, o que significa que o Poder Público precisa criar instrumentos para se amoldar à realidade social.

Ninguém quer o regresso aos primórdios da humanidade, onde os recursos eram escassos, mas é indispensável desacelerar para ter um olhar cauteloso para a realidade, se beneficiar dos avanços positivos e sustentáveis sem abrir mão dos valores e princípios, que são por vezes encobertos.

Constatou-se que a economia colaborativa é um método de consumo respeitável no quesito sustentabilidade, ainda que de forma indireta, tendo em vista que esse modelo de economia visa antingir os objetivos do consumo de forma a sanar as necessidades do consumidor, ou seja, a exemplo da Uberização, o consumidor não quer um carro, mas sim chegar ao seu objetivo final, o que colabora para a mudança de hábitos tradicionais.

Argumentou-se no sentido de que o Código de Defesa do Consumidor constitui o instrumento de equilíbrio nas relações consumeristas, apesar de necessitar de ser utilizado juntamente a outros enfoques do ordenamento jurídico brasileiro para conseguir se adaptar às necessidades da nova economia, para assim atender totalmente as demandas relacionadas.

Conclui no sentido de buscar sempre uma segurança jurídica por meio das normas existentes e a necessidade de constante adaptação e consequente transformação da lei ao caso 
concreto diante do cenário em que a demanda se encontra. Se faz importante haver uma ponderação do diálogo das fontes normativas, com o intuito de proteger ambos os lados da relação de consumo.

\section{REFERÊNCIAS}

ABREU, Paula Santos de. A Globalização e a Proteção do Consumidor como Direito Fundamental. Revista do Programa de Mestrado em Direito do UniCEUB, Brasília, v. 2, n. 1, p. 5-19, jan./jun. 2005.

Análise do Consumo Colaborativo realizada pela CNDL e SPC Brasil em agosto de 2019. Disponível em: <https://www.spcbrasil.org.br/wpimprensa/wpcontent/uploads/2019/08/analise_consumo_colaborativo_2019.pdf> Acesso em 25 mar. 2020.

ALVES, Eliete Tavelli. Parassubordinação e uberização do trabalho : algumas reflexões. Rio de Janeiro : Lumen Juris, 2019.

ANDRADE, Daniela Rafael; DANTAS, Rodolfo Lima. UBER: a oportunidade dos sonhos ou o pesadelo do direito do trabalho. Direito do trabalho e direito processual do trabalho : estudos avançados/ coordenação Fernanda Nigri Faria ... [et al.]. --São Paulo: LTr, 2017.

BAUMAN, Zygmunt; MAY, Tim. Aprendendo a pensar com a sociologia. Rio de Janeiro: Jorge Zahar, 2010.

BAUMAN, Zygmunt. Globalização: as consequências humanas. Rio de Janeiro: Jorge Zahar, 1999.

BAUMAN, Zigmunt. Modernidade líquida. Rio de Janeiro: Jorge Zahar, 2001.

BAUMAN, Zigmunt. Vida para Consumo: a transformação de pessoas em mercadoria. Rio de Janeiro: Jorge Zahar, 2008.

BECK, Ulrich. Sociedade de risco: rumo a uma outra modernidade. São Paulo: 34, 2010

BOTSMAN, Rachel; ROGERS, Roo. O que é meu é seu: como o consumo colaborativo vai mudar o nosso mundo. Porto Alegre: Bookman, 2011.

BRASIL. Constituição da República Federativa do Brasil de 1988. Brasília, 1988. Disponível em: <http://www.planalto.gov.br/ccivil_03/constituicao/constituicao.htm> Acesso em 25 mar.2020.

BRASIL. Institui as diretrizes da Política Nacional de Mobilidade Urbana. Lei 12.587, de 3 de janeiro de 2012. Brasília, 2012. Disponível em: < 
http://www.planalto.gov.br/ccivil_03/_ato2011-2014/2012/lei/112587.htm> Acesso em: 14 mar.2020.

BRASIL. Lei no 8.078, de 11 de setembro de 1990. Dispõe sobre o Código de Defesa do Consumidor. Disponível em: <http://www.planalto.gov.br/ccivil_03/leis/18078.htm>. Acesso em: 18 mar. 2020.

BRASIL. Lei $\mathbf{n}^{\mathbf{0}}$ 12.965, de 23 de abril de 2014. Estabelece princípios, garantias, direitos e deveres para o uso da Internet no Brasil. Disponível em:

<http://www.planalto.gov.br/ccivil_03/_ato2011-2014/2014/lei/112965.htm>. Acesso em 18 mar. 2020.

BRASIL. Supremo Tribunal Federal. Recurso Extraordinário n. 1054110. Relator: Min. Roberto Barroso; julgado em 05 de maio 2019. Disponível em

<http://portal.stf.jus.br/processos/detalhe.asp?incidente=5206938> Acesso em 26 mar. 2020.

CAVALIERI FILHO, Sérgio. Programa de direito do consumidor. 2. ed. São Paulo: Atlas, 2010.

BARROS, Ana Cirne Paes de. Uber: O Consumo Colaborativo e as Lógicas do Mercado. Disponível em <http://anais-comunicon2015.espm.br/GTs/GT5/24_GT5_BARROS.pdf> Acesso em 18 mar. 2020.

ENTREVISTA. Núcleo de Pesquisa em Estudos Culturais - Npec: 28 de nov. de 2011.

Disponível em: <https://www.youtube.com/watch?v=1miAVUQhdwM> Acesso em 17 mar. 2020.

FARIA, Fernanda Nigri et al. (Coord). Direito do trabalho e direito processual do trabalho: estudos avançados. São Paulo: LTr, 2017.

FRAGOSO, Kaliandra; BONATO, Kamile; SOARES, Isaak Newton. UBER - Consumo Colaborativo ou Nova Relação de Trabalho? Disponível em:

<http://portalintercom.org.br/anais/sul2019/resumos/R65-1131-1.pdf> Acesso em: 25 mar. 2020.

FRANCO, David Silva; FERRAZ, Deise Luiza da Silva. Uberização do trabalho e acumulação capitalista. Cadernos EBAPE.BR, v. 17, Edição Especial, Rio de Janeiro, Nov. 2019. Disponível em <http://www.scielo.br/scielo.php?script=sci_arttext\&pid=S167939512019000700844\&tlng=pt> Acesso em: 25 mar.2020.

IGREJA CATÓLICA. Papa (2013 -Francisco). Carta Encíclica Laudato Si: sobre o cuidado da casa comum. São Paulo: Paulinas, 2015. Disponível em:

$<$ http://www.vatican.va/content/francesco/pt/encyclicals/documents/papafrancesco_20150524_enciclica-laudato-si.pdf >. Acesso em: 18 mar. 2020.

LEME, Ana Carolina Reis Paes. Da máquina à nuvem: caminhos para o acesso à justiça pela via de direitos dos motoristas da Uber I Ana Carolina Reis Paes 
Leme. - São Paulo: LTr, 2019.

LEONARD, A. A história das coisas: da natureza ao lixo, o que acontece com tudo que consumimos. Rio de Janeiro: Zahar, 2011.

NUNES, Luiz Antônio Rizzatto. Curso de direito do consumidor. 12. ed. São Paulo: Saraiva, 2018.

OLIVEIRA, Luiz Nayjhon de Souza; LIMA, Antônio Raniel Silva. Economia compartilhada aliado ao setor de serviços: uma revisão sistemática de trabalho brasileiros. Id on Line Rev.Mult. Psic., 2018, vol.12, n.42, Supl. 1, p. 365-377. ISSN: 1981-1179.

PASQUALOTTO, Adalberto; BUBLITZ, Michelle Dias. Desafios do Presente e do Futuro para as Relações de Consumo ante Indústria 4.0 e a Economia Colaborativa. Revista de Direito, Globalização e Responsabilidade nas Relações de Consumo. V. 3, n. 2, p. 62 - 81, Maranhão, 2017. Disponível em:

<https://indexlaw.org/index.php/revistadgrc/article/view/2526/pdf> Acesso em: 24 mar. 2020.

SANDEL, Michael J. Justiça: o que é fazer a coisa certa. 15. ed. Rio de Janeiro: Civilização Brasileira, 2014.

UBER. Termos e Condições. Disponível em: <https://www.UBER.com/legal/terms/br/> . Acesso em: 18 mar. 2020.

UBER. Uma carta de Dara Khosrowshahi, CEO. Disponível em:

$<$ https://investor.uber.com/a-letter-from-our-ceo/?_ga=2.166348222.166906536.15851855621802651252.1585185562> Acesso em 25 mar. 2020. 